\title{
PENGARUH POLA PEMBERIAN MAKAN TERHADAP STATUS GIZI BALITA DI WILAYAH KERJA PUSKESMAS ASTANAJAPURA KABUPATEN CIREBON TAHUN 2019
}

\section{Lilis Yuliarsih, Toha Muhaimin dan Syamsul Anwar}

Fakultas Keperawatan Universitas Muhammadiyah Jakarta dan Fakultas Keperawatan Universitas Indonesia Jakarta

Email: yuliarsih@yahoo.co.id, tohamuhaimin@gmail.com dan syamsul_nisa@yahoo.co.id

\section{Abstract}

Nutritional status is a very important thing parents should know, especially those who have children under five years old because it is a golden period associated with growth and subsequent development. Nutritional status can be influenced by several factors including food consumption patterns. The purpose of this study was to determine the effect of feeding patterns on the nutritional status of children under five in the working area of Astanajapura Public Health Center in Cirebon District in 2019. The research design used in this study was descriptive correlational with cross sectional approach. The population in this study were all children aged 1-5 years in the working area of Astanajapura Health Center in 2019 as many as 4231 toddlers, the sampling technique used was simple random sampling technique. Data analysis using univariate analysis showed that most toddlers (61\%) had poor diet and most toddlers (70.5) had both bivariate and multivariate nutritional status with multiple logistic regression tests. The results of the bivariate analysis showed that there was an effect of feeding patterns on the nutritional status of children under five years old with a $p$ value ( $p$-value $=0.017 \leq$ $0.05)$. and by evaluating the program in order to improve the degree of public health.

Keywords: Pattern offeeding, nutritional status, toddlers.

\section{Abstrak}

Status gizi merupakan hal yang sangat penting harus diketahui orang tua terutama yang memiliki anak usia dibawah lima tahun karena merupakan masa emas yang terkait dengan pertumbuhan dan perkembangan masa selanjutnya.status gizi dapat dipengaruhi oleh beberapa faktor diantaranya adalah pola konsumsi makanan. Tujuan penelitian ini adalah untuk mengetahui pengaruh pola pemberian makan terhadap status gizi balita di wilayah kerja puskesmas Astanajapura kabuapten Cirebon tahun 2019. Desain penelitian yang digunakan dalam penelitian ini adalah deskriptif korelasional dengan pendekatan cross sectional. Populasi dalam penelitian ini adalah seluruh anak usia 1-5 tahun di wilayah kerja puskesmas Astanajapura Tahun 2019 sebanyak 4231 balita, tekhnik pengambilan sampel yang digunakan adalah tekhnik simple random sampling. Analisa data menggunakan analisis univariat, bivariat dan multivariat dengan uji regresi logistik ganda. Hasil 
analisis univariat menunjukan bahwa sebagian besar balita (61\%) memiliki pola makan baik dan sebagian besar balita memiliki status gizi baik (70,5\%). Hasil analisis multivariat menunjukkan terdapat pengaruh pola pemberian makan terhadap status gizi balita dengan nilai $\mathrm{p}(p$-value $=0,017 \leq 0,05)$. Berdasarkan hasil penelitian yang menunjukan bahwa masih terdapatnya balita dengan status gizi kurang maka diharapkan pihak Puskesmas Astanajapura dapat memberikan pelayanan kepada masyarakat khususnya keluarga yang memiliki anak balita dengan mengutamakan pelayanan primer berupa promotif dan preventif dengan melakukan penyuluhan kesehatan agar dapat meningkatkan derajat kesehatan masyarakat terutama dalam meningkatkan status gizi balita dengan menurunkan dan menekan angka kejadian gizi kurang atau pun gizi buruk.

Kata kunci: Balita, Pola pemberian makan, Status Gizi.

\section{Pendahuluan}

Status gizi balita merupakan hal penting yang harus diketahui oleh setiap orang tua. Perlunya perhatian lebih dalam tumbuh kembang di usia balita didasarkan fakta bahwa kurang gizi yang terjadi pada masa emas ini bersifat sangat penting untuk masa selanjutnya (Marimbi, 2010).

Status gizi pada anak Makin bertambah usia maka semakin anak bertambah pula kebutuhannya, konsumsi makanan dalam keluarga dipengaruhi jumlah, frekuensi dan jenis makanan yang diberikan (Setyawati \& Hartini, 2018).

Status gizi di Jawa barat menjadi masalah kesehatan yang serius. Terdapat 14 Kabupaten di propinsi Jawa Barat yang termasuk dalam kategori serius, salah satu diantaranya adalah Kabupaten Cirebon yaitu (19,6 \%) dengan status gizi kurang dan $(6,4 \%)$ status gizi buruk (Kemenkes, 2018). Kecamatan Astanajapura Kabupaten Cirebon pada tahun 2017 merupakan salah satu wilayah dengan angka kejadian status gizi kurang dan gizi buruk yang cukup tinggi yaitu (5,2\%) (Ulfah et al., 2018).

Melihat pentingnya peran gizi dalam mencapai tujuan SDGs, maka sektor gizi perlu mendapat perhatian khusus dan menjadi tanggung jawab bersama baik dari praktisi kesehatan maupun dari masyarakat umum, sehingga dapat terbentuk masyarakat yang sehat dan sejahtera (Kemenkes, 2018).

Tujuan dari penelitian ini adalah terindentifikasinya pola pemberian makan terhadap status gizi Balita di wilayah kerja Puskesmas Astanajapura Kabupaten Cirebon tahun 2019.

\section{Metode Penelitian}

Penelitian ini menggunakan desain deskriptif korelasional dengan pendekatan studi cross sectional Pengambilan sampel menggunakan teknik simple random sampling terdiri dari 146 sampel. Kriteria inklusi pada penelitian ini yaitu ibu yang memiliki anak usia 1-5 tahun dan bersedia menjadi responden. Kriteria ekslusi yaitu responden yang mengundurkan diri, anak yang sakit atau tahap pengobatan dan keluarga yang tidak menetap. 


\section{Hasil dan Pembahasan}

\section{A. Hasil Penelitian}

1. Analisis Univariat

\section{Tabel 1}

Distribusi responden berdasarkan karakteristik balita di wilayah kerja puskesmas Astanajapura kabupaten Cirebon tahun 2019

\begin{tabular}{lcccc}
\hline \multicolumn{1}{c}{ Variabel } & Kategori & Frekuensi & Prosentase & Jumlah \\
\hline \multirow{2}{*}{ Usia Balita } & 1-3 Tahun & 99 & $67,8 \%$ & \\
& 3-5 Tahun & 47 & $32,2 \%$ & \\
\multirow{2}{*}{ Jenis Kelamin Balita } & Laki-laki & 64 & $43,8 \%$ & \multirow{2}{*}{$\mathbf{1 4 6}$} \\
& Perempuan & 82 & $56,2 \%$ & \multirow{2}{*}{ Riwayat Infeksi } \\
\cline { 1 - 4 } & Pernah & 124 & $84,9 \%$ & \\
& Tidak Pernah & 22 & $15.1 \%$ & \\
\hline
\end{tabular}

Tabel 2

Distribusi responden berdasarkan karakteristik ibu di wilayah kerja puskesmas Astanajapura Kabupetan Cirebon tahun 2019

\begin{tabular}{|c|c|c|c|c|}
\hline Variabel & Kategori & Frekuensi & $\begin{array}{c}\text { Prosen } \\
\text { tase }\end{array}$ & Jumlah \\
\hline \multirow{2}{*}{ Pekerjaan } & Tidak bekerja & 128 & $87,7 \%$ & \multirow{8}{*}{146} \\
\hline & Bekerja & 18 & $12,3 \%$ & \\
\hline \multirow{2}{*}{ Tingkat Pendidikan } & Rendah ( $\leq$ SMP $)$ & 3 & $2,1 \%$ & \\
\hline & Tinggi (> SMP) & 143 & $97,9 \%$ & \\
\hline \multirow{2}{*}{ Jumlah Anggota Keluarga } & $(\leq 4$ orang $)$ & 79 & $54,1 \%$ & \\
\hline & (> 4 orang) & 67 & $45,9 \%$ & \\
\hline Pendapatan Keluarga & $\begin{array}{c}\text { Rendah }(\leq \\
\text { UMR }) \\
\text { Tinggi }(>\text { UMR })\end{array}$ & $\begin{array}{l}122 \\
24\end{array}$ & $\begin{array}{l}83,6 \% \\
16,4 \%\end{array}$ & \\
\hline Pengetahuan Ibu & $\begin{array}{c}\text { Kurang } \\
\text { Baik }\end{array}$ & $\begin{array}{c}19 \\
127\end{array}$ & $\begin{array}{l}13 \% \\
87 \%\end{array}$ & \\
\hline
\end{tabular}

Tabel 3

Distribusi responden berdasarkan gambaran pola makan dan status gizi balita di wilayah kerja puskesmas Astanajapura kabupaten Cirebon tahun 2019

\begin{tabular}{ccccc}
\hline Variabel & Kategori & Jumlah & Prosentase & N \\
\hline \multirow{2}{*}{ Pola Makan } & Kurang Baik & 57 & $39 \%$ & \\
\multirow{2}{*}{ Status Gizi } & Baik & 89 & $61 \%$ & \multirow{2}{*}{146} \\
& Gizi kurang & 43 & $29,5 \%$ & \\
\hline
\end{tabular}




\section{Analisis Bivariat}

\section{Tabel 4}

Distribusi frekuensi responden berdasarkan pengaruh pola pemberian makan,tingkat pendidikan ibu, pengetahuan ibu, jenis kelamin, pendapatan keluarga,jumlah anggota keluarga dan riwayat infeksi terhadap status gizi balitadi wilayah kerja puskesmas Astanajapura Kabupaten Cirebon tahun 2019

\begin{tabular}{|c|c|c|c|c|c|c|c|c|}
\hline \multirow{3}{*}{ Pola makan } & \multicolumn{4}{|c|}{ Status gizi } & \multirow{2}{*}{\multicolumn{2}{|c|}{ Total }} & \multirow{3}{*}{ Sig. } & \multirow{3}{*}{ OR $(95 \% \mathrm{CI})$} \\
\hline & \multicolumn{2}{|c|}{ Gizi kurang } & \multicolumn{2}{|c|}{ Gizi baik } & & & & \\
\hline & $\mathrm{n}$ & $\%$ & $\mathrm{n}$ & $\%$ & $\mathrm{~N}$ & $\%$ & & \\
\hline Kurang & 24 & $42.1 \%$ & 33 & $57.9 \%$ & 57 & $100 \%$ & & 2,679 \\
\hline Baik & 19 & $21.3 \%$ & 70 & $78.7 \%$ & 89 & $100 \%$ & 0.007 & $(1,314-$ \\
\hline Total & 43 & $29.5 \%$ & 103 & $70.5 \%$ & 146 & $100 \%$ & & $5,512)$ \\
\hline \multirow{3}{*}{$\begin{array}{c}\text { Tingkat } \\
\text { pendidikan }\end{array}$} & \multicolumn{4}{|c|}{ Status gizi } & \multirow{2}{*}{\multicolumn{2}{|c|}{ Total }} & & $\mathrm{OR}(05 \% \mathrm{CI})$ \\
\hline & $\mathrm{Giz}$ & kurang & & baik & & & Sig. & OR $(95 \% \mathrm{Cl})$ \\
\hline & $\mathrm{n}$ & $\%$ & $\mathrm{n}$ & $\%$ & $\mathrm{~N}$ & $\%$ & & \\
\hline Rendah & 2 & $66,7 \%$ & 1 & $33,3 \%$ & 3 & $100 \%$ & & 4,975 \\
\hline Tinggi & 41 & $28,7 \%$ & 102 & $71,3 \%$ & 143 & $100 \%$ & 0.153 & $(2,270-$ \\
\hline Total & 43 & $29,5 \%$ & 103 & $70,5 \%$ & 146 & $100 \%$ & & $5,626)$ \\
\hline \multirow{3}{*}{$\begin{array}{l}\text { Pengetahuan } \\
\text { ibu }\end{array}$} & \multicolumn{4}{|c|}{ Status gizi } & \multirow{2}{*}{\multicolumn{2}{|c|}{ Total }} & & \\
\hline & $\mathrm{Giz}$ & kurang & & baik & & & Sig. & OR (95\%) \\
\hline & $\mathrm{n}$ & $\%$ & $\mathrm{n}$ & $\%$ & $\mathrm{~N}$ & $\%$ & & \\
\hline Kurang baik & 8 & $42.1 \%$ & 11 & $57.9 \%$ & 19 & $100 \%$ & & 1.912 \\
\hline Baik & 35 & $27.6 \%$ & 92 & $72.4 \%$ & 127 & $100 \%$ & 0.195 & (0.710- \\
\hline Total & 43 & $29.5 \%$ & 103 & $70.5 \%$ & 146 & $100 \%$ & & $5.147)$ \\
\hline \multirow{3}{*}{ Pekerjaan ibu } & \multicolumn{4}{|c|}{ Status gizi } & \multirow{2}{*}{\multicolumn{2}{|c|}{ Total }} & $\mathrm{Si \sigma}$ & OR (95\%) \\
\hline & Giz & kurang & & baik & & & SIg. & UK $(93 \%)$ \\
\hline & $\mathrm{n}$ & $\%$ & $\mathrm{n}$ & $\%$ & $\mathrm{~N}$ & $\%$ & & \\
\hline Bekerja & 40 & $31,3 \%$ & 88 & $68,8 \%$ & 128 & $100 \%$ & & 2.273 \\
\hline Tidak Bekerja & 3 & $16,7 \%$ & 15 & $83,3 \%$ & 18 & $100 \%$ & 0.204 & $(0,623-$ \\
\hline Total & 43 & $29,5 \%$ & 103 & $70,5 \%$ & 146 & $100 \%$ & & $.8295)$ \\
\hline \multirow{3}{*}{ Jenis kelamin } & \multicolumn{4}{|c|}{ Status gizi } & \multirow{2}{*}{\multicolumn{2}{|c|}{ Total }} & $\mathrm{Si \sigma}$ & OR (95\%) \\
\hline & Giz & kurang & & baik & & & & \\
\hline & $\mathrm{n}$ & $\%$ & $\mathrm{n}$ & $\%$ & $\mathrm{~N}$ & $\%$ & & \\
\hline Laki-laki & 22 & $34,4 \%$ & 42 & $65,6 \%$ & 64 & $100 \%$ & & 1.522 \\
\hline Perempuan & 21 & $25,6 \%$ & 61 & $74,4 \%$ & 82 & $100 \%$ & 0.249 & $(0,744-$ \\
\hline Total & 43 & $29,5 \%$ & 103 & $70,5 \%$ & 146 & $100 \%$ & & $3,112)$ \\
\hline \multirow{3}{*}{$\begin{array}{l}\text { Pendapatan } \\
\text { Keluarga }\end{array}$} & \multicolumn{4}{|c|}{ Status gizi } & & & & \\
\hline & \multicolumn{2}{|c|}{ Gizi kurang } & \multicolumn{2}{|c|}{ Gizi baik } & \multicolumn{2}{|c|}{ Total } & Sig. & OR $(95 \%)$ \\
\hline & $\mathrm{n}$ & $\%$ & $\mathrm{n}$ & $\%$ & $\mathrm{~N}$ & $\%$ & & \\
\hline Rendah & 37 & $30,3 \%$ & 85 & $69,7 \%$ & 122 & $100 \%$ & & 1.306 \\
\hline Tinggi & 6 & $25,0 \%$ & 18 & $75,0 \%$ & 24 & $100 \%$ & 0.601 & $(0,480-$ \\
\hline Total & 43 & $29,5 \%$ & 103 & $70,5 \%$ & 146 & $100 \%$ & & $3,555)$ \\
\hline \multirow{3}{*}{$\begin{array}{c}\text { Jml anggota } \\
\text { keluarga }\end{array}$} & & Sta & is giz & & & & Sia & $05 \%)$ \\
\hline & $\mathrm{Giz}$ & kurang & & baik & & & Sig. & UR $(95 \%)$ \\
\hline & $\mathrm{n}$ & $\%$ & $\mathrm{n}$ & $\%$ & $\mathrm{~N}$ & $\%$ & & \\
\hline
\end{tabular}




\begin{tabular}{|c|c|c|c|c|c|c|c|c|}
\hline$(>4)$ & 24 & $30,4 \%$ & 55 & $69,6 \%$ & 79 & $100 \%$ & & 1.102 \\
\hline$(\leq 4)$ & 19 & $28,4 \%$ & 48 & $71,6 \%$ & 67 & $100 \%$ & 0.789 & $(0,539-$ \\
\hline Total & 43 & $29,5 \%$ & 103 & $70,5 \%$ & 146 & $100 \%$ & & $2,255)$ \\
\hline \multirow{3}{*}{$\begin{array}{c}\text { Riwayat } \\
\text { infeksi }\end{array}$} & \multicolumn{4}{|c|}{ Status gizi } & \multirow{2}{*}{\multicolumn{2}{|c|}{ Total }} & \multirow{3}{*}{ Sig. } & \multirow{3}{*}{ OR $(95 \%)$} \\
\hline & \multicolumn{2}{|c|}{ Gizi kurang } & \multicolumn{2}{|c|}{ Gizi baik } & & & & \\
\hline & $\mathrm{n}$ & $\%$ & $\mathrm{n}$ & $\%$ & $\mathrm{~N}$ & $\%$ & & \\
\hline Pernah & 38 & $30,6 \%$ & 86 & $69,4 \%$ & 124 & $100 \%$ & & 1,502 \\
\hline Tidak Pernah & 5 & $22,7 \%$ & 17 & $77,3 \%$ & 22 & $100 \%$ & 0.453 & $(0,229,-$ \\
\hline Total & 43 & $29,5 \%$ & 103 & $70,5 \%$ & 146 & $100 \%$ & & 1,936) \\
\hline
\end{tabular}

\section{Analisis Multivariat}

Tabel 5

Seleksi Bivariat Uji Regresi Logistik Sederhana

\begin{tabular}{lc}
\hline \multicolumn{1}{c}{ Variabel } & Sig. $(<0.25)$ \\
\hline Pola Makan & 0.008 \\
\hline Pendidikan Ibu & 0.178 \\
\hline Pengetahuan Ibu & 0.207 \\
\hline Pekerjaan Ibu & 0.182 \\
\hline Jenis Kelamin Balita & 0.250 \\
\hline Pendapatan Anggota Keluarga & 0.596 \\
\hline Jumlah Anggota Keluarga & 0.789 \\
\hline Riwayat Penyakit Infeksi & 0.443 \\
\hline
\end{tabular}

Tabel 6

Model Terakhir Multivariat Pengaruh Pola Makan, Tingkat Pendidikan, dan Pekerjaan Ibu terhadap Status Gizi Balita di Wilayah Kerja Puskesmas Astana Japura Kabupaten Cirebon tahun 2019

\begin{tabular}{lcccc}
\hline \multicolumn{1}{c}{ Variabel } & B & OR & Sig. & OR $(\mathbf{9 5 \%}$ C.I $)$ \\
\hline Pola Makan & -0.931 & 0.394 & 0.017 & $0.183-0.849$ \\
\hline Pendapatan Keluarga & 0.275 & 1.317 & 0.628 & $0.433-4.010$ \\
\hline Pengetahuan Ibu & 0.367 & 1.444 & 0.554 & $0.428-4.876$ \\
\hline Pendidikan Ibu & -2.310 & 0.099 & 0.088 & $0.007-1.413$ \\
\hline Pekerjaan Ibu & 1.392 & 4.025 & 0.087 & $0.817-19.830$ \\
\hline
\end{tabular}

\section{B. Pembahasan}

\section{Pengaruh pola pemberian makan terhadap status gizi balita.}

Sebagian besar balita memiliki status gizi baik (70,5\%) dan sebagian besar balita memiliki pola makan baik (61\%). Hasil analisis menunjukan adanya pengaruh pola pemberian makan terhadap status gizi balita dengan nilai $p$ value 0,017 ( $p$ value $<0,05$ ).

Hal ini sejalan dengan penelitian sebelumnya yang menyatakan bahwa terdapat hubungan antara pola pemberian makan dengan status gizi balita dengan nilai $p=0,000$ ( $p$ value $<0,05)$ (Subarkah \& Nursalam, 2016). Hal ini sejalan dengan penelitian sebelumnya yang menyatakan bahwa terdapat 
hubungan yang signifikan antara pola makan dengan status gizi balita dengan $\mathrm{p}=0,000$ (p value < 0,05) (Mulyaningsih, 2008).

Pola makan dapat memberikan gambaran asupan gizi mencakup jenis, jumlah, dan jadwal dalam pemenuhan nutrisi. Pola pemberian makan harus berpedoman pada gizi seimbang mecakup asupan gizi yang cukup sesuai kebutuhan dan mengkonsumsi makanan yang beragam agar dapat mencapai status gizi normal (Kemenkes, 2015).

\section{Pengaruh pendapatan keluarga terhadap status gizi balita}

Berdasarkan hasil penelitian dapat diketahui bahwa sebagian besar responden memiliki pendapatan rendah atau di bawah UMR setempat $(69,7 \%)$. Namun dengan pendapatan keluarga yang rendah hampir sebagian besar balita memiliki status gizi baik $(69,7 \%)$. Berdasarkan hasil analisis menunjukan bahwa tidak ada pengaruh antara pendapatan keluarga terhadap status gizi balita dengan nilai $\mathrm{p}=0,0601$ ( $\mathrm{p}$ value $>0,05)$.

Hal ini sejalan dengan penelitian sebelumnya yang menyatakan bahwa tidak ada hubungan yang signifikan antara pendapatan keluarga dengan status gizi balita ( $\mathrm{p}$ value $=0,352$ ) (Mirayanti, 2012). Berbeda dengan peneitian sebelumnya yang menyatakan bahwa ada hubungan anatara pendapatan keluarga dengan status gizi balita dengan nilai $\mathrm{p}=0,031$ ( $\mathrm{p}$ value $<0,05$ ) (Wardani,2017). Begitu pula dengan penelitian (Berg et al., 2016) yang menyatakan bahwa terdapat hubungan antara tingkat pendapatan dengan status gizi balita.

Pendapatan rendah menyebabkan daya beli rendah, namun jika ibu mampu memilih jenis makan yang baik dan mengatur pola makan dengan baik dan dapat memelihara kesehatan agar anak tidak sering sakit maka status gizi anak yang baik dapat dipertahankan. (Supariasa, n.d.).

\section{Pengaruh pengetahuan ibu terhadap status gizi balita}

Berdasarkan hasil penelitian dapat diketahui bahwa sebagian besar ibu yang memiliki balita memiliki tingkat pengetahuan yang baik $(72,4 \%)$, dari sebagian ibu dengan tingkat pengetahuan kurang baik, memiliki balita dengan status gizi baik $(57,9 \%)$. Hasil uji statistik diperoleh nilai $\mathrm{p}=0,554$ ( $\mathrm{p}$ value > 0,005) , maka dapat disimpulkan bahwa tidak ada pengaruh pengetahuan terhadap status gizi balita.

Berdasarkan penelitian (Mulyaningsih, 2008) menunjukan bahwa tidak ada hubungan antara pengetahuan dengan status gizi dengan nilai $\mathrm{p}=0,806$. Menurut (OKTARIANA, 2009) bahwa ada hubungan antara tingkat pengetahuan ibu dengan status gizi balita.

Meskipun pengetahuan rendah namun jika didukung dengan dengan faktor lain seperti pendapatan yang cukup maka status gizi anak akan baik.

\section{Pengaruh pendidikan ibu terhadap status gizi balita}

Berdasarkan hasil penelitian menunjukan bahwa tingkat pendidikan ibu sebagian besar adalah berpendidikan tinggi (>SMP) 97,9\%. Hasil analisis 
menyatakan bahwa 71,3\% ibu berpendidikan tinggi memiliki anak balita dengan status gizi baik dan 66,7\% ibu berpendidikan rendah memiilki balita dengan status gizi baik. Berdasarkan hasil uji statistik diperoleh nilai $p=0,153$ ( $\mathrm{p}$ value $>0,005$ ) ini menunjukan bahwa tidak ada pengaruh antara pendidikan terhadap status gizi balita.

Berdasarkan penelitian sebelumnya (Firmana, 2015) menyatakan bahwa terdapat hubungan antara tingkat pendidikan terhadap status gizi balita dengan nila $\mathrm{p}=0,022$ ( $\mathrm{p}$ value $<0,05$ ). Menurut Hadisaputra (2009) menyatakan bahwa tidak ada hubungan anatara pendidikan ibu dengan status gizi balita dengan nilai $\mathrm{p}=0,563$.

Semakin tinggi tingkat pendidikan maka semakin mudah memahami suatu informasi dan mengimplementasikan dalam kehidupan sehari-hari khususnya tentang kebutuhan gizi anak (Atmarita, 2004).

Disamping tingkat pendidikan, kemampuan ibu angat penting dalam mengelola sumber daya keluarga dan mengatur pola makan anak sehingga anak dapat selalu terpelihara kesehatan dan pola makan dapat tetap terjaga sehingga status gizi baik.

\section{Pengaruh jumlah anggota keluarga terhadap status gizi balita}

Berdasarkan hasil penelitian diketahui bahwa sebagian besar responden memiliki jumlah anggota keluarga $>4$ orang dan memiliki balita dengan status gizi baik $(69,6 \%)$ dan $71,6 \%$ balita dengan status gizi baik terdapat pada keluarga dengan jumlah anggota keluarga yang $<4$ orang. Hasil analisis menyatakan bahwa tidak ada pengaruh jumlah anggota keluarga terhadap status gizi balita dengan $p=0,789$ ( $p$ value $>0,05)$.

Berdasarkan penelitian sebelumnya (Firmana, 2015) menyatakan bahwa terdapat hubungan antara jumlah anak dengan status gizi dengan nilai $\mathrm{p}=0,008$ hal ini sejalan dengan penelitian Hadisaputra (2009) yang menyatakan bahwa terdapat hubungan antara jumlah anak dengan status gizi balita dengan nilai $\mathrm{p}=0,015$. Berbeda dengan penelitian Dewati (2004) yang menyatakan bahwa tidak terdapat hubungan antara jumlah anggota keluarga dengan status gizi anak.

Jumlah anggota keluarga yang banyak dapat berpengaruh terhadap jumlah dan distribusi makanan dalam keluarga sehingga dapat berdampak terhadap kecukupan gizi anak khususnya, selain itu dengan jumlah anak yang banyak dapat menyebabkan perhatian yang kurang merata terhadap anak. Hal ini dapat berdampak terhadap kecukupan konsumsi makanan dan status gizi anak (Miko,2003).

Jika jumlah anggota keluarga banyak namun jumlah pendapatan keluarga tinggi maka kebutuhan dan dsitribusi makanan akan terpenuhi dan status gizi dapat dipertahankan dengan baik

\section{Pengaruh Pekerjaan terhadap status gizi balita}


Berdasarkan hasil penelitian dapat diketahui bahwa sebagian besar ibu adalah bekerja dan memiliki balita dengan status gizi baik $(68,8 \%)$ dan dari sebagian ibu yang tidak bekerja memiliki balita dengan status gizi baik $(71,6 \%)$. Hasil uji statistik diperoleh nilai $\mathrm{p}=0,204$ ( $\mathrm{p}$ value $>0,05$ ) maka dapat disimpulkan bahwa tidak ada pengaruh ibu bekerja terhadap status gizi balita.

Berdasarkan penelitian (Firmana, 2015) menyatakan bahwa terdapat hubungan antara pekerjaan dengan status gizi dengan nilai $\mathrm{p}=0,000$ ( $\mathrm{p}$ value $<$ 0,005). Menurut Miko terdapat 22,4\% status gizi kurang mempunyai ibu yang bekerja lebih banyak dibandingkan ibu yg tidak bekerja $(19,9 \%)$ hal ini menun jukan bahwa terdapat hubungan antara pekerjaan ibu dengan status gizi anak. Berdasarkan hasil penelitian Hadisaputra (2009) dinyatakan bahwa tidak ada hubungan status pekerjaan ibu dengan status gizi balita dengan nilai $\mathrm{p}=0,998$.

Anak balita merupakan usia dimana anak masih ketergantungan terhadap orang tua dalam pemenuhan kebutuhan gizi . Oleh karena itu perhatian orang tua sangat diperlukan dalam merawat, memperhatikan dan memenuhi kebutuhan kesehatan anak terutama kebutuhan gizi. Ibu yang tidak bekerja dapat berperan banyak dan memiliki waktu yang cukup dalam pengaturan pola makan anak dan ibu yang bekerja hampir tidak cukup waktu untuk merawat dan memperhatikan pola makan anak (Handayani, 2008).

Jika ibu bekerja namun bisa mengelola dan melibatkan orang lain untuk delegasi dalam merawat anak maka kebutuhan anak akan terpenuhi.

\section{Pengaruh Jenis kelamin terhadap status gizi balita}

Berdasarkan hasil penelitian dapat diketahui bahwa sebagian besar dari responden adalah jenis kelamin perempuan $(74,4 \%)$ memiliki status gizi baik, dan diantara responden laki -laki sebagian $(65,6 \%)$ memiliki status gizi baik. Hasil analisis menunjukan bahwa jenis kelamin tidak berpengaruh secara signifikan terhadap status gizi balita dengan nilai $\mathrm{p}=0,294$ ( $\mathrm{p}$ value $>0,05$ ).

Hal ini sejalan dengan penelitian sebelumnya yang menyatakan bahwa tidak ada hubungan antara jenis kelamin dengan status gizi balita dengan nilai $\mathrm{p}=0,550$ (Kusnandar, 2014). Begitu pula menurut Swastika (2012) menyatakan dalam hasil penelitiannya bahwa tidak ada hubungan anatara jenis kelamin dengan status gizi balita dengan nilai $\mathrm{p}=0,393$.

Kebutuhan zat gizi pada anak laki-laki berbeda dengan anak perempuan dan biasanya lebih tinggi pada anak laki-laki karena memiliki aktivitas fisik yang lebih tinggi (Khumaidi, 2009).

Selain perbedaan karakteristik jenis kelamin, kebutuhan gizi seseorang dipengaruhi pula oleh banyak faktor diantaranya adalah faktor internal individu, aktifitas maupun faktor pola asuh orang tua dan keadaan keluarga.

\section{Pengaruh Riwayat infeksi terhadap status gizi balita}

Berdasarkan hasil penelitian dapat diketahui bahwa sebagian besar balita $(69,4 \%)$ pernah mengalami penyakit infeksi seperti diare, ISPA, thypoid, 
ataupun DBD namun hasil penelitian menunjukan bahwa balita tersebut memiliki status gizi baik. Sementara diantara balita yang tidak pernah mengalami penyakit infeksi $(77,3 \%)$ memiliki status gizi baik. Hasil analisis menunjukan bahwa riwayat infeksi tidak berpengaruh terhadap status gizi balita dengan nilai $\mathrm{p}=0,569$ ( $\mathrm{p}$ value $>0,05)$.

Hasil penelitian ini sejalan dengan hasil penelitian sebelumnya bahwa tidak ada hubungan antara penyakit infeksi dengan status gizi dengan nilai $\mathrm{p}=$ 0,14 (Hadisaputra , 2009 ). Begitu pula menurut Suhendi (2007) dalam penelitiannya menyatakan bahwa tidak ada hubungan status gizi dengan infeksi dengan nilai $p=0,815$. Menurut Nababan (2007) ada pengaruh riwayat infeski terhadap status gizi disamping kemiskinan, kurang pengetahuan, dan kurangnya pelayanan kesehatan ( $p>0,05)$.

Anak yang terkena infeksi yang berulang dan kronis akan mengalami gangguan gizi dan gangguan imunitas. Demikian juga pada anak dengan asupan yang kurang, maka daya tahan tubuh dapat melemah dan dalam keadaan demikian akan mudah diserang infeksi, yang dapat mengurangi nafsu makan dan akhirnya anak dapat menderita kurang gizi (Depkes RI, 2007).

\section{Kesimpulan}

Sebagian besar balita memiliki pola makan baik (61\%). Sebagian besar balita memiliki status gizi baik (70,5\%).. Ada pengaruh pola makan terhadap status gizi balita dan terdapat 4 faktor konfonding yaitu pendapatan keluarga, pendidikan, pengetahuan, dan pekerjaan ibu. 


\section{BIBLIOGRAFI}

Berg, A. M., Mol, S. T., Kismihók, G., \& Sclater, N. (2016). The role of a reference synthetic data generator within the field of learning analytics. Journal of Learning Analytics, 3(1), 107-128.

Kemenkes, R. I. (2015). Profil kesehatan Indonesia tahun 2014. Jakarta: Kemenkes RI.

Kemenkes, R. I. (2018). Hasil utama RISKESDAS 2018. Online) Http://Www. Depkes. Go. Id/Resources/Download/Info-Terkini/Materi_rakorpop_2018/Hasil\% 20Riskesdas, 202018.

Marimbi, H. (2010). Tumbuh kembang, status gizi dan imunisasi dasar pada balita. Yogyakarta: Nuha Medika, 26-27.

Mulyaningsih, F. (2008). Hubungan antara pengetahuan ibu tentang gizi balita dan pola makan balita terhadap status gizi balita di kelurahan Srihardono kecamatan Pundong. Jurusan Pendidikan Teknik Boga Dan Busana. Universitas Negeri Yogyakarta.

Oktariana, W. (2009). Analisis Perkembangan Kinerja Keuangan (Studi Kasus Pada Perusahaan Industri Rokok di Bursa Efek Indonesia Tahun 2004-2006). Universitas Muhammadiyah Surakarta.

Setyawati, V. A. V., \& Hartini, E. (2018). Buku Ajar Dasar Ilmu Gizi Kesehatan Masyarakat. Deepublish.

Subarkah, T., \& Nursalam, R. P. D. (2016). Pola Pemberian Makan Terhadap Peningkatan Status Gizi Pada Anak Usai 1-3 Tahun. Jurnal Injec, 1(2), 146-154.

Supariasa, I. (n.d.). DN, dkk. 2002. Penilaian Status Gizi. Buku Kedokteran. Jakarta: $E G C$.

Ulfah, M., Kamasturyani, Y., \& Ramadani, P. M. (2018). Hubungan Pengetahuan Tentang Pencegahan Penyakit Kusta Dengan Risiko Penularan Kusta Di Wilayah Kerja Puskesmas Losari, Puskesmas Kedaton Dan Puskesmas Babakan Kabupaten Cirebon. Jurnal Kesehatan Mahardika, 5(2). 